\title{
Metas de produção em cooperativas de recicláveis: tensões entre ambiente cooperativo e atuação competitiva
}

\author{
Production targets in recycling cooperatives: tensions between cooperative \\ environment and competitive performance
}

\section{Les objectifs de production en coopératives recyclables: les tensions entre l'environnement coopératif et performance compétitive}

Las metas de producción en cooperativas reciclables: tensiones entre el ambiente de cooperación y desempeño competitivo

\author{
José Ronaldo S. Fernandes* \\ (ronaldo@crca.org.br) \\ André Pires* \\ (anpires@puc-campinas.edu.br)
}

Recebido em 09/06/2015; revisado e aprovado em 11/08/2015; aceito em 10/10/2015

DOI: http:/ /dx.doi.org/10.20435/1984042X2016203

\begin{abstract}
Resumo: Este artigo visa refletir sobre tensões que surgem a partir do estabelecimento de metas de produção em cooperativas de reciclagem. A partir de um estudo de caso que envolveu experiências no âmbito de uma cooperativa de segundo grau do município de Campinas, SP, este texto busca evidenciar que a implantação das metas trouxe como consequência aumento e previsibilidade da renda, demandas dos(as) cooperados(as). Em nosso entendimento, o sucesso do sistema de metas se deu porque sua adoção não rompeu com os processos de escolha e decisão das cooperativas, mas adaptou-se a eles.

Palavras-chave: cooperativismo; catadores; educação.

Abstract: This article aims to point out some tensions that arise that arise from the establishment of collective production targets for recycling cooperatives. Based on a case study under a recycle cooperative in the city of Campinas, São Paulo, this text seeks to show that the implementation of the production goals brought as a consequence increase and predictability of income. In this sense, the adoption of collective production target did not break the processes of choice and decision of cooperatives, but has adapted to them.

Key words: cooperatives; "catadores"; education.

Résumé: Cet article vise à réfléchir sur les tensions qui découlent de la mise en place d'objectifs de production dans les coopératives de recyclage. D'après une étude de cas portant sur des expériences sous coopérative dans la ville de Campinas, São Paulo, ce texte cherche à montrer que la mise en œuvre des objectifs apporté comme une augmentation des conséquences et de la prévisibilité des revenus, les exigences de (la) coopération (as). À notre avis, le succès du système de ciblage était parce que son adoption n'a pas rompu avec les processus de choix et de décision des coopératives, mais a adapté pour eux.

Mots-clés: coopératives; "catadores"; éducation.

Resumen: Este artículo tiene como objetivo reflexionar sobre las tensiones que surgen desde el establecimiento de los objetivos de producción en las cooperativas de reciclaje. A partir de un estudio de caso que involucra experimentos bajo un instituto cooperativo en la ciudad de Campinas, São Paulo, este texto pretende demostrar que la aplicación de las metas trajo como consecuencia aumento y la previsibilidad de los ingresos, las demandas de (la) cooperativa (as). En nuestra opinión, el éxito del sistema de focalización se debió a su adopción no se rompió con los procesos de elección y decisión de las cooperativas, pero se ha adaptado a ellos. Palabras clave: cooperativos; "catadores"; educación.
\end{abstract}

\section{INTRODUÇÃO}

Este artigo visa refletir sobre inquietações vivenciadas na relação cotidiana com cooperativas de recicláveis na região de Campinas, SP. São tensões que surgem a partir das expectativas criadas sobre as possibilidades da proposta cooperativista, como instrumento de transformação social e sua prática cotidiana. Tensões que poderiam ser sintetizadas na seguinte questão: como construir um ambiente cooperativo, emancipador e, ao mesmo tempo, desenvolver mecanismos de competição para atuação no mercado? Trata-se de problemas a serem levados em conta quando se consideram as relações entre esses empreendimentos e o mercado capitalista. A ideia de um mercado

\footnotetext{
* Pontifícia Universidade Católica de Campinas (PUC-Campinas), São Paulo, Brasil.
} 
autorregulável como princípio controlador da própria sociedade humana, como afirmou o economista húngaro Karl Polanyi (POLANYI, 2000, p. 75), é algo que pode colocar em risco a própria vida civilizada se não fossem os mecanismos de regulação oferecidos pelos Estados de Bem-Estar Social modernos. Em essência, as forças do mercado capitalista, como nos ensinou Karl Marx há mais de cem anos, são desumanizadoras e, para garantir sua sobrevivência, as cooperativas precisam atuar de forma eficiente nesse espaço de competição.

Ambiente cooperativo, atuação competitiva: é possível conciliar? Como desenvolver mecanismos para a convivência de um coletivo de trabalhador(a)es quando todos os estímulos da sociedade são na direção de um "individualismo escrachado", para usar expressão de Maria da Conceição Tavares (TAVARES, 2014, p. 22). Numa cooperativa, as regras de organização do empreendimento são definidas coletivamente. No entanto é muito comum ouvir de cooperado(a)s que "se sou dono, faço o que eu quero". A despeito das possibilidades presentes no formato do cooperativismo vinculado à Economia Solidária, que serão vistos a seguir, a vivência cotidiana dessa construção coletiva aponta para diversos pontos de tensão vividos entre as expectativas e as práticas cooperativistas. Dentre tantos pontos de tensão possíveis, tais como em relação aos papéis de gênero no ambiente das cooperativas e os desafios para a construção de uma estrutura operacional eficiente, apenas para citarmos dois, no presente artigo iremos focalizar o estabelecimento de metas de produção numa cooperativa popular.

$\mathrm{O}$ texto se divide em quatro partes, além desta Introdução. Na sequência, apresentaremos as principais referências teóricas que fundamentaram as observações e interpretações aqui tratadas relativas à economia solidária. Na terceira parte, descreveremos o método e o contexto da cooperativa de segundo grau estudada. Na quarta, apresentaremos os desafios e tensões que emergiram quando se estabeleceram as metas de produção. Ao final, sintetizaremos nossas observações nos comentários finais.

\section{ECONOMIA SOLIDÁRIA}

Entendemos, tal como sugere Leite (2009), que não existe um consenso em relação à definição de economia solidária. Trata-se, como de fato ocorre com os chamados fenômenos sociais, de um debate acerca desse tema em que se apresentam diferentes posições sobre os limites e possibilidades dessa forma de organização social. Sem ter a pretensão de esgotar este debate, nos limitaremos a fazer um pequeno recorte a fim de contextualizar o estudo de caso em questão.

De uma maneira um tanto quanto esquemática, podemos dizer que parte das discussões sobre economia solidária diz respeito ao sentido que esse termo possui em relação às transformações pelas quais passaram as sociedades capitalistas nas últimas décadas. De um lado, há os que enfatizam vínculos históricos entre as experiências atuais e aquelas ocorridas no início do século XIX na Inglaterra, inspiradas por Richard Owen. Nesse enquadramento, importância é conferida à potência que essa forma de organização social possui em termos da transformação das relações de produção capitalistas, uma vez que são experiências em que há apropriação coletiva dos meios de produção. Na observação de Leite, se "sobressai a idéia da transformação social das relações de produção capitalistas e sua substituição pelos princípios socialistas de igualdade e solidariedade, baseados na idéia de autogestão e controle operário sobre a produção" (LEITE, 2009, p. 32).

Para outros, como indica (LEITE, 2009), há um sentido novo que pode ser conferido à economia solidária, resultante da chamada crise da sociedade salarial das sociedades capitalistas observada nas últimas décadas do século XX. Vários autores têm apontado para o fato de que reestruturação produtiva capitalista, dirigindo-se para formas de produção e de consumo mais flexíveis, alteraram profundamente as relações de trabalho (CASTELLS, 2000; CASTEL, 1998; HARVEY, 1994, SENNETT, 1999, entre outros). As consequências dessa reestruturação do capitalismo e da atuação do Estado são bastante conhecidas. Podemos notar numa crescente deterioração das condições de vida do trabalhador substancializada pela queda dos rendimentos das famílias, pelo aumento das 
taxas de desemprego, do trabalho temporário e pelo declínio das redes de proteção social. A inserção estável e até certo ponto permanente no mercado de trabalho já não é mais uma expectativa plausível para um grande número de pessoas. É importante frisar que essa chamada crise na sociedade salarial ou do trabalho não atinge somente os segmentos mais vulneráveis, tais como os trabalhadores com menor qualificação, ou os mais jovens. Trata-se de um processo amplo que alcança os mais qualificados e também aqueles que têm emprego. Assim, as transformações socioeconômicas das últimas décadas colocaram à tona a incapacidade das sociedades atuais em absorver todos os indivíduos que estão em condições de trabalhar (OFFE, 1995; GORZ, 2003). No bojo desse processo de crise do trabalho assalariado, surgem as primeiras iniciativas de formação de cooperativas de trabalho e de produção autogestionários que passaram a ser reconhecidas pelo nome de economia solidária (LEITE, 2009).

Embora se possam reconhecer vínculos com as experiências socialistas do século XIX, essas "novas" cooperativas ampliam o debate à luz do atual contexto socioeconômico ao introduzir, por exemplo, questões relacionadas às desigualdades de gênero e ambientais, além de se imaginarem não como alternativa, mas convivendo, de maneira tensa como pretendemos sugerir nesse texto, com o sistema capitalista de produção.

Esse processo, com efeito, é marcado por dilemas, tais como este retratado por Lima (2004): de que maneiras as propostas de cooperativas podem simultaneamente dar continuidade à luta por uma sociedade mais igualitária dentro do contexto do desenvolvimento capitalista? Será possível isso? Ao recuperar suas tipologias, questiona-se sobre como evitar que esses empreendimentos se transformem em "falsas cooperativas ou cooperfraudes", isto é, locais "em que o trabalho autogestionário termina por ser funcional pela flexibilidade que possibilita no uso da força de trabalho, permitindo redução de custos e aumentando a competitividade das empresas" (LIMA, 2004, p. 46). Ou que essas iniciativas sucumbam à "tese da degeneração das cooperativas", na qual as necessidades de integração ao sistema capitalista fazem com que esses empreendimentos passem a aceitar os ditames do mercado, incorporando o lucro e o trabalho assalariado (LIMA, 2004, p. 47).

Compreendemos os empreendimentos econômicos solidários a partir de sua natureza híbrida, vale dizer, são formas de organização social que atuam nas quatro formas de interação econômica descritas por Polanyi, a saber, a domesticidade, a reciprocidade, a redistribuição e o mercado (FRANÇA FILHO; LAVILLE, 2004 apud BARRETO; PAULA, 2009). Dito de outro modo, a economia solidária "seria responsável por religar o econômico ao social, combinado a reciprocidade às lógicas redistributivas e de barganha visando reforçar a auto-regulação da sociedade civil" (LEITE, 2009, p.35). Explorar algumas tensões que decorrem dessa "natureza híbrida" é um dos intentos deste trabalho, como dito na Introdução.

\section{CONTEXTO}

Cabe inicialmente afirmar que este trabalho possui um caráter eminentemente descritivo e se baseia em observações a partir de um estudo de caso único realizado na Central Solidária de Vendas (RECICLAMP), cooperativa de segundo grau, do município de Campinas, SP. Essas observações foram geradas a partir da experiência profissional de um dos autores deste texto no Centro de Referência em Cooperativismo e Associativismo de Campinas (CRCA) e, depois, na RECICLAMP, descritos a seguir, desde sua fundação.

Em 1999, ocorreram as primeiras iniciativas em direção à formulação do CRCA de Campinas. A criação do CRCA, em boa medida, foi estimulada pela Campanha da Fraternidade daquele ano, cujo tema era "A Fraternidade e os Desempregados" e o lema "Sem trabalho ... por quê?", os quais buscavam discutir os níveis alarmantes de desemprego e as possibilidades de auto-organização do(a)s trabalhadore(a)s. Em 2002, o CRCA foi fundado como uma organização não governamental com a missão de "contribuir para a construção de uma sociedade justa e solidária, na qual o desenvolvimento das potencialidades humanas, a vida digna e a cidadania sejam realidade para todos". Durante os anos iniciais, acabou se dedicando quase que exclusivamente à incubação de cooperativas 
populares de coleta, manuseio e comercialização de materiais recicláveis. As atividades do CRCA foram descontinuadas em meados de 2013, sendo alguma de suas atribuições assumidas pela RECICLAMP, constituída em 2008, como resultado da assessoria do CRCA.

A RECICLAMP se configura como cooperativa de segundo grau, ou seja, uma cooperativa de cooperativas. Suas principais funções são vendas, coleta e assessoria técnica em gestão para os empreendimentos associados. Em junho de 2014, a RECICLAMP abrigava sete cooperativas com um total de 187 cooperado(a)s . Destas, seis situam-se no município de Campinas, SP, e participam do Programa de Geração de Trabalho e Renda da Prefeitura Municipal de Campinas, lançado em 2001, com a destinação do material da coleta seletiva do município para grupos dispostos a se organizar em cooperativas. A outra cooperativa localiza-se em Valinhos, SP, município contíguo à Campinas, e participa do programa de coleta seletiva municipal recebendo cem por cento do material reciclável coletado pela empresa de prestação de serviços de limpeza pública contratada deste município.

Catadores de materiais recicláveis, desempregados com dificuldades para se (re) inserir no mercado de trabalho e pessoas sem experiência profissional, mas com necessidade de auferir renda para sua sobrevivência, compõem a população das cooperativas. Nesse ambiente, sobressai a participação das mulheres, maioria das cooperadas. São pessoas definidas como em situação de vulnerabilidade social. Ao definir quem são os usuários da Política Nacional de Assistência Social, o Ministério do Desenvolvimento Social e Combate à Fome estabelece as situações que podem ser consideradas de vulnerabilidade:

[...] famílias e indivíduos com perda ou fragilidade de vínculos de afetividade, pertencimento e sociabilidade; ciclos de vida; identidades estigmatizadas em termos étnico, cultural e sexual; desvantagem pessoal resultante de deficiências; exclusão pela pobreza e, ou, no acesso às demais políticas públicas; uso de substâncias psicoativas; diferentes formas de violência advinda do núcleo familiar, grupos e indivíduos; inserção precária ou não inserção no mercado de trabalho formal e informal; estratégias e alternativas diferenciadas de sobrevivência que podem representar risco pessoal e social. (BRASIL, 2004).

Dessa população, nomeada e definida pelo Estado a partir de algo que lhes falta, é que trataremos neste texto.

Acolhendo o entendimento do Movimento Nacional dos Catadores de Recicláveis na construção da sua identidade, bem como a CBO 5.192-5 (Código Brasileiro de Ocupações), que reconhece essa atividade como uma categoria profissional, passaremos a nos referir a essa população como Catadores e Catadoras, independentemente se fazem ou não catação na rua, ou simplesmente Cooperado(a)s e Cooperadas.

Retomando a proposta original iniciada pelo trabalho do CRCA, a opção pelo cooperativismo decorreu das possibilidades que esse tipo de organização proporciona não apenas para a geração de renda, mas também para o desenvolvimento das potencialidades humanas, em função do ambiente organizacional e societário propício. Singer (2002, p. 21) contempla esse aspecto: "a autogestão tem como mérito principal não a eficiência econômica (necessária em si), mas o desenvolvimento humano que proporciona aos praticantes".

É nessa perspectiva que o cooperativismo foi impulsionado nas cooperativas associadas, como forma de organização que permite construir novas relações no e a partir do empreendimento econômico autogestionário. Condições divergentes daquelas encontradas na tradicional organização capitalista. Como visto na seção anterior, trata-se de uma forma de organização do trabalho que busca transcender as relações de exploração presentes na compra e venda da força de trabalho, propiciando, dessa maneira, novas possibilidades de organização da própria sociedade. $\mathrm{Na}$ definição da Secretaria Nacional de Economia Solidária (SENAES) (BRASIL, 2012, p. 120), Economia Solidária é "o conjunto de atividades econômicas - de produção, distribuição, consumo, poupança e crédito - organizadas e realizadas solidariamente por trabalhadore(a) s sob a forma coletiva e autogestionária. Esse conceito geral explicita os valores e princípios fundamentais da Economia Solidária: cooperação, autogestão, solidariedade e dimensão econômica". 
No Brasil, a Economia Solidária conseguiu avanços significativos através da mobilização para implementação das políticas públicas do setor com a criação da SENAES, Conselho Nacional de Economia Solidária e Fórum Brasileiro de Economia Solidária (FBES), em 2003. Entre 2003 e 2010, foram mais de R 200 milhões investidos (BRASIL, 2012, p. 12-26). Segundo o Sistema Nacional de Informações de Economia Solidária (SIES), são 19.708 Empreendimentos Econômicos Solidários (EES) que reúnem mais de 1,4 milhão de trabalhadora(e)s (BRASIL, 2013, p. 2-4).

\section{METAS DE PRODUÇÃO NUMA COOPERATIVA POPULAR.}

As cooperativas populares enfrentam o grande desafio de serem viáveis economicamente, o que, para esse tipo de organização, significa gerar resultado capaz de proporcionar renda digna para seus trabalhador(a)es cumprindo a legislação vigente da atividade. Para tal, a qualidade da gestão é um aspecto crítico. Ora, esse desafio também é posto para as empresas tradicionais, porém, estas utilizam um arsenal de técnicas de administração num ambiente em que a cooperação, autogestão e solidariedade não são os princípios fundamentais das relações de trabalho. São, portanto, aplicadas em um ambiente distinto daquele de uma cooperativa autogestionária. Aqui temos um ponto de tensão: métodos de gestão utilizados sob a lógica das empresas tradicionais podem ser implantados em empreendimentos autogestionários sem corromper seus princípios de solidariedade, cooperação, auto-gestão, gestão democrática? Técnicas específicas deveriam ser desenvolvidas pelas cooperativas populares?

Para ilustrar esse ponto, reproduzimos um episódio envolvendo um executivo de uma consultoria internacional que detém tecnologia de um método de organização da produção e que se dispôs a "ajudar" cooperativas populares de Campinas. O executivo se inquietava e relutava diante das dificuldades de implantação da metodologia numa cooperativa popular: "Essa metodologia é um sucesso em grandes empresas, que possuem profissionais extremamente qualificados. Por que não funcionaria numa cooperativa?" $\mathrm{O}$ executivo não conseguia aceitar que o medo da demissão e o despotismo da hierarquia de uma empresa tradicional são fatores decisivos para o sucesso desse método e não possuem o mesmo efeito nos chamados empreendimentos econômicos autogestionários. A diretoria, os executivos e/ ou os acionistas decidem o que é melhor para a empresa, e aquilo desce estrutura abaixo, sem muitos questionamentos. Não é assim que ocorre numa cooperativa. Os trabalhador(a)s são ativos nas decisões e saberão, no seu saber e não no nosso, a partir das suas necessidades e não das nossas, o que é bom para eles e o que não é. Com os riscos de errarem também, como em qualquer organização.

Agravante é a constatação de que as cooperativas populares enfrentam o estigma de serem vistas pela sociedade, em geral, e pelas autoridades, em particular, como projeto social, uma ação filantrópica, induzindo as cooperativas ao erro de não se ocuparem com a boa gestão. Lançando mão de um jargão muito utilizado em brincadeira de crianças, são tratadas como um ator "café com leite", aquele com quem ninguém se importa mesmo que infrinja as regras da brincadeira ou do jogo. Depreende-se que sua ação não interferirá de maneira significativa nos resultados dos demais jogadores, no caso concreto, do mercado de materiais recicláveis.

A implantação das metas de produção nas cooperativas de recicláveis da RECICLAMP surgiu a partir da insegurança das trabalhadoras em relação à renda: num mês, produzia-se muito, e a renda era boa, noutro, muito pouco, e a renda era ruim. Oscilava como os trilhos de uma montanha russa, o que comprometia o frágil orçamento doméstico das cooperadas que, como vimos, compõem a maioria. O que inquietava era a instabilidade. Era comum ouvir o questionamento das cooperadas: como fazer uma compra parcelada sem ter certeza da renda no final do mês? Muitas se animavam com um mês bom e faziam os famosos "carnezinhos". E aí nos meses seguintes a renda caia. Como pagar o carnê?

A partir da identificação dessa inquietação, membros da equipe do CRCA com experiência em gestão empresarial concluíram que a implantação de metas poderia ser uma alternativa para reduzir a forte variação da 
produção, funcionando como uma reguladora do nível de produção.

Meta é instrumento consolidado em empresas tradicionais e diretamente relacionado aos resultados econômicos esperados pelos gestores e/ou proprietários. Estendese a produtos intangíveis como vendas, marketshare, rentabilidade e por aí vai, dependendo da criatividade dos gestores e dos estudiosos da administração.

Ao longo desses 15 anos de atividades junto às cooperativas identificamos que qualquer instrumento de controle ou procedimento de organização é imediatamente associado ao ideário de uma empresa, pejorativamente. No caso tratado por este artigo, independente do resultado, a ideia de que meta "é coisa de empresa" prevalece na cabeça de muitos cooperado(a)s. Mesmo cuidando para que sua implantação se dê através de um processo de debate democrático e seus parâmetros de medição sejam definidos pelo(a)s próprio(a) $s$ trabalhadore(a)s, tal percepção permanece para alguns.

Estávamos diante do desafio de implantar um instrumento com essa carga simbólica de exploração do(a) trabalhador(a) num empreendimento autogerido pelo(a) s próprio(a)s trabalhadore(a)s. A pura e simples transferência do instrumento de um ambiente (empresarial) para outro (cooperativo) projetava uma catástrofe, feriria de morte o princípio da autogestão, por se tratar de algo impositivo definido por quem está "fora" da operacionalização da atividade. O caminho foi aquele sempre escolhido para um empreendimento dessa natureza: ir para o diálogo: apresentar a ferramenta e avalia-la diretamente com os cooperado(a)s. E assim foi. E ainda assim, ouvia-se amiúde "isso aqui tá virando empresa".

Foi a determinação das diretorias das cooperativas que garantiu a implantação das metas, pois eram elas que sofriam a pressão das cooperadas para que a renda não tivesse tanta variação e identificaram nas metas um bom equacionamento para o problema. Conseguiram também vislumbrar que a implantação de metas de produção poderia contribuir para corrigir uma distorção do sistema de remuneração das cooperativas. Como o cálculo da renda é por horas trabalhadas, muitos cooperado(a)s "enrolavam" para fazer mais horas sem produzirem, o que prejudicava as demais. A meta de produção contribuiu para minimizar essa atitude, pois a cooperada deve produzir nas horas trabalhadas, e sua contribuição é medida objetivamente.

Então, como é que funciona a meta de produção nas cooperativas associadas à RECICLAMP?

Antes vamos dar uma rápida passada pelo fluxo de materiais, desde o momento da coleta até a finalização do produto para venda. $\mathrm{O}$ material reciclável gerado nas residências, comércio e indústria chega até a cooperativa de diversas maneiras. Pode ser coletado pela própria RECICLAMP ou por empresas contratadas pela Prefeitura local e disposto na cooperativa. Parte desse material é levado até a cooperativa pelas próprias empresas geradoras; em algumas regiões, os próprios moradores levam o material até a cooperativa. Esse material é disposto na área de recebimento e passa inicialmente por um processo de pré-triagem no qual os cooperado(a)s retiram os materiais de maior volume e "embegam" o restante. Esses begues são pesados antes de serem enviados para as mesas de triagem.

Cabe um parênteses para esclarecer que todas as cooperativas da RECICLAMP utilizam mesas para separação do material. Não utilizam esteiras, pelo investimento que esse equipamento requer e por faltar análise específica de quanto esse equipamento poderia contribuir para melhorar a produtividade com relação à saúde do trabalhador.

É nas mesas de triagem que o composto de recicláveis, inicialmente caracterizado pelas quatro famílias clássicas - papel, plástico, metal, vidro - se converterá em dezenas de produtos diferentes. $\mathrm{O}$ material triado tem dois destinos: estoque final, onde o produto está disponível para venda, e estoque intermediário. Desta última área, o produto segue para prensagem, e os fardos, para o estoque final.

\footnotetext{
${ }^{1}$ A palavra é um aportuguesamento construído pelos cooperado(a)s a partir da palavra inglesa big bag, utilizada pela indústria para designar contentores flexíveis feitos de um tipo de plástico com volume que varia entre 250 e 3.000 litros. Foi adotado desde 2003 pelas cooperativas para acondicionamento e deslocamento/ transporte de material reciclável. Os cooperado(a)s aportuguesaram a palavra para begue e criaram variações como "embegar", "embegador" e "embegado".
} 
Ao analisar os processos internos das cooperativas, foi identificado que o ponto crítico é a triagem. Pela mesa de triagem passam entre $75 \%$ e $90 \%$ de todo o material manuseado pela cooperativa. O volume complementar é retirado no processo de pré-triagem. O ritmo de trabalho na mesa de triagem é que define o ritmo de todas as demais atividades na cooperativa: ele "puxa" e "empurra" as atividades dentro do processo de produção, ou seja, a pré-triagem e a alimentação das mesas têm que trabalhar num ritmo para não faltar material para triagem; a retirada de material triado dos recipientes coletores instalados nas mesas tem que acontecer no ritmo para não interromper o processo. A prensagem também acontece num ritmo diretamente proporcional ao trabalho das mesas. Somente as atividades administrativas da cooperativa é que seguem outro ritmo.

A forma de medição e seu quantitativo foram definidos pelo(a)s trabalhadore(a)s, cada cooperativa definindo seus parâmetros. Não houve variação significativa de uma para outra, a não ser nos quantitativos. A medição em todas elas é feita em quilos de material triado por hora por cooperado(a). O número varia entre 30 e $50 \mathrm{~kg} /$ hora/ cooperado(a). A medição está a cargo da Coordenação de Produção. Essa função foi criada para garantir a implantação dos processos definidos coletivamente. Fugiria dos propósitos deste texto a discussão sobre essa função, que enfrentou desafio equivalente ao das metas.

A Coordenação de Produção registra o peso do begue e a mesa para qual foi destinado. Ao final do dia, soma-se o peso total dos begues triados pela respectiva mesa e se faz a comparação com a meta da mesa. Para cálculo da meta, a Coordenação de Produção multiplica as horas trabalhadas pelos cooperado(a) s de uma determinada mesa pela meta-hora da cooperativa. Exemplo: uma mesa com quatro triadoras trabalhando num turno de 5,5 horas numa cooperativa cuja meta-hora é $40 \mathrm{~kg}$ /cooperado(a)/hora tem como meta triar $880 \mathrm{~kg}$ em cada turno.

As metas são definidas por mesa, porém, dependendo da cooperativa, a mesa é composta por apenas uma cooperada; outras trabalham em dupla; outras em duas duplas.

O tratamento dado ao não cumprimento da meta difere entre as cooperativas, e até dentro da mesma cooperativa pode haver tratamento diferenciado a depender dos motivos que levaram ao não cumprimento do objetivo. Exemplos: 1) a diretoria da cooperativa simplesmente ignora o não cumprimento, mas isso tem desestimulado as cooperadas que cumprem a meta. Normalmente a renda é menor nessas cooperativas; 2 ) solidariamente, pode acontecer um mutirão de cooperado(a) $\mathrm{s}$ voluntários para compensar a meta de um cooperado(a) que não cumpriu seu objetivo por motivo que os voluntários reconheceram que não foi negligência ou falta de empenho do cooperado(a);3) o cumprimento da meta pode se dar pela extensão do turno de trabalho do cooperado(a) até o atingimento da meta sem a remuneração dessas horas; 4) o caso extremo é o desconto da quantidade de horas equivalentes aos quilos não triados.

Uma consequência não prevista que surgiu a partir do estabelecimento das metas foi uma adequação no posicionamento dos cooperado(a)s na mesa de triagem. Na mesa com quatro trabalhadore(a)s, eles identificaram posições na mesa que lhes eram mais favoráveis. A mesa de triagem padrão da cooperativas mede $2,10 \mathrm{~m} \times 1,20 \mathrm{~m}$. A organização do(a)s trabalhadore(a)s na mesa é dois cooperado(a)s de cada lado, constituindo assim, duas duplas. Cada dupla é responsável pela separação de um conjunto de 15 a 20 materiais diferentes. $\mathrm{O}$ ato da triagem pode ser separado em quatro etapas, a saber: 1. pegar um determinado material; 2 . classificá-lo; 3. localizar seu recipiente de destino; 4 . dispô-lo nesse recipiente. Esse movimento exige uma rotação do corpo para a direita ou esquerda dependendo do local onde está posicionado o referido recipiente. São as características de maior ou menor facilidade para execução desse movimento ou de maior ou menor habilidade com a mão esquerda ou com a direita, que contribuem para definir a posição de cada cooperado(a) à mesa de triagem. Relevante registrar que "a triagem é coisa de mulher", como afirmado por um cooperado. Ele tem razão, no grupo atual de aproximadamente 200 cooperado(a)s, nenhum homem está na atividade de triagem.

Retomemos a fala: "esta cooperativa está virando empresa". O significado dessa expressão demonstra que para estes cooperado(a)s as cooperativas não deveriam 
ter regras, metas e objetivos. Na percepção dos cooperado(a)s mais antigos e que ajudaram a construir a cooperativa, essa fala denotaria o comportamento de pessoas que compreendem a cooperativa de catadores como lugar de passagem, um espaço "filantrópico" até que consigam um emprego "de verdade" com "carteira assinada". São trabalhadore(a) $s$ que não se identificam com a cooperativa e não têm compromisso com seu presente e futuro. De fato, há elevados índices de rotatividade que ainda persiste nas cooperativas: no primeiro semestre de 2014 foi de $13,0 \%$ do total de associados.

A despeito dessas contestações e resistências, indicadores de que não se tratou de um processo fácil, a implantação da meta de produção mudou para melhor a renda da maioria dos cooperado(a)s e lhes trouxe o mínimo de estabilidade. Segundo dados do Relatório Econômico-financeiro, atualmente elaborado pela Equipe Executiva da RECICLAMP, os resultados da implantação do sistema de metas foi muito positivo. Contribuiu substancialmente para o aumento da renda e de redução de sua flutuação. Em termos nominais, observou-se, na renda média dos cooperado(a)s do primeiro semestre de 2014, acréscimo de 193,3\% em relação ao mês de junho de 2006, momento em que se iniciou a implantação do sistema de metas. No tocante à flutuação da renda, considerando a renda média do primeiro semestre de 2014, houve variação máxima de $5,2 \%$ acima da média em janeiro de 2014 e 6,1\% abaixo da renda média mensal em maio. Flutuações não tão bruscas como as verificadas em momentos anteriores.

Acreditamos que o estabelecimento de metas está em sintonia com as orientações da Conferência Nacional de Economia Solidária, a qual destacou que esses empreendimentos têm de ser economicamente viáveis. No caso em questão, a renda média dos cooperado(a)s no primeiro semestre de 2014 foi de $\mathrm{R} \$ 1.190,77$, para uma jornada de 36 horas semanais, ou seja, 1,64 Salário Mínimo em valores de 2014. Em manifestação durante a Expocatadores/2013, o Prof. Paul Singer, titular da SENAES, ao defender a nova Lei do Cooperativismo de Trabalho (Lei 12.690/2012) foi contundente: “será que vale a pena ter um empreendimento desses existindo se ele não é capaz de gerar um salário mínimo de renda e garantir condições mínimas de trabalho e benefíciosaos seus cooperado(a)s?".

\section{COMENTÁRIOS FINAIS}

Pela vivência do trabalho junto às cooperativas, a aplicação de instrumentos de gestão empresarial nas cooperativas populares deve estar atrelada à sua re-significação em benefício do(a)s trabalhadore(a)s. Este texto buscou mostrar que, quando foram implantadas, as metas de produção foram discutidas com os cooperado(a)s e cooperadas assim como o significado daquele ato num empreendimento solidário. Vimos que, para muitos cooperado(a)s, o estabelecimento de metas significava que a cooperativa estava "virando uma empresa" demonstrando claramente que para estes cooperado(a)s as cooperativas não deveriam ter metas e objetivos. Tratava-se, como visto, de um lugar de passagem, sem comunhão com sua identidade e compromisso com seu presente e futuro. A implantação da meta de produção, no entanto, mudou para melhor a renda dos cooperado(a)s.

Em nosso entendimento, o relativo sucesso do sistema de metas nas cooperativas associadas deu-se porque sua implantação respeitou as especificidades dos empreendimentos econômicos solidários. De maneira diversa ao que supostamente ocorreria caso esse sistema fosse implantado numa empresa capitalista, o processo de identificação da necessidade e de implantação dessa ferramenta foi feito de maneira coletiva, não sem resistências, com a participação direta das cooperadas e cooperado(a)s. Nesse sentido, a adoção do sistema de metas não rompeu os processos de escolha e decisão das cooperativas, mas adaptou-se a eles. E este, o ponto que queremos enfatizar neste texto.

\section{REFERÊNCIAS}

BARRETO, Raquel de Oliveira; PAULA, Ana Paula Paes. Os dilemas da economia solidária: um estudo acerca da dificuldade de inserção dos indivíduos na lógica cooperativista. Cadernos EBAPE.BR, Rio de Janeiro, v. 7, n. 2, artigo 2, jun. 2009.

BRASIL. Ministério do Desenvolvimento Social e do Combate à Fome. 2004. Disponível em: <http:// www.mds.gov.br/falemds/perguntas-frequentes/ assistencia-social/assistencia-social/usuario/pnas- 
-politica-nacional-de-assistencia-social-institucional>. Acesso em: 31 out. 2014.

. Ministério do Trabalho e Emprego/Secretaria Nacional de Economia Solidária. Avanços e Desafios para as Políticas Públicas de Economia Solidária no governo Federal - 2003/2010. Brasília, 2012.

Ministério do Trabalho e Emprego/Secretaria Nacional de Economia Solidária. Acontece SENAES, Edição Especial. Brasília, 2013.

CASTEL, Robert. As metamorfoses da questão social: uma crônica do salário. Petrópolis, RJ: Vozes, 1998.

CASTELLS, Manuel. A sociedade em rede. São Paulo: Paz e Terra, 2000.

GORZ, André. Metamorfoses do trabalho: crítica da razão econômica. São Paulo: Annablume, 2003.

HARVEY, David. A condição pós-moderna. São Paulo: Edições Loyola, 1994.
LEITE, Marcia de Paula. A economia solidária e o trabalho associativo. Revista Brasileira de Ciências Sociais, v. 24, n. 69, fev. 2009.

LIMA, Jacob Carlos Lima. O trabalho autogestionário em cooperativas de produção: o paradigma revisitado. Revista Brasileira de Ciências Sociais, v. 19, n. 56, out. 2004.

OFFE, Claus . Full Employment: Asking the Wrong Question? Dissent, p. 77-81, Winter 1995.

POLANYI, Karl. A grande transformação: as origens da nossa época. Rio de Janeiro: Elsevier, 2000.

SENNETT, Richard. The Corrosion of Character. New York: W.W. Norton \& Company, 1999.

SINGER, Paul. Introdução à economia solidária. 1. ed. São Paulo: Fundação Perseu Abramo, 2002.

TAVARES, Maria da Conceição. A era das disto(pias). Revista Insight Inteligência, ano XVI, n. 64, jan./fev./ mar. 2014 